\title{
Osmotic adjustment to water stress in pearl millet (Pennisetum americanum [L.] Leeke) under field conditions
}

\author{
I. E. HENSON*, V. MAHALAKSHMI, F. R. BIDINGER \& G. ALAGARSWAMY *Plant \\ Breeding Institute, Maris Lane, Trumpington, Cambridge CB2 2LQ, England and International \\ Crops Research Institute for the Semi-Arid Tropics, Patancheru P.O., Andhra Pradesh 502 324, India
}

Received 26 May 1981; accepted for publication 24 August 1981

\begin{abstract}
Osmotic adjustment, a mechanism whereby plants maintain positive turgor despite low water potential $(\Psi)$, was investigated in pearl millet (Pennisetum americanum [L.] Leeke) in three types of field experiment at Hyderabad, India:
\end{abstract}

(1) Osmotic adjustment during the growing season was evaluated by comparing solute potential $\left(\Psi_{\mathrm{S}}\right)$ of leaves taken at midday from irrigated and droughted plots and allowed to rehydrate in the laboratory. The degree of seasonal adjustment was also estimated by comparing observed values of $\Psi_{S}$ in the field with those expected if $\Psi_{\mathrm{S}}$ decreased solely in proportion to water loss. Both types of assessment indicated the maximum seasonal adjustment to be about $0.2 \mathrm{MPa}$. The cultivars BJ 104 and Serere 39 differed in their capacity to adjust osmotically over the season; Serere 39 was least able to osmoregulate.

(2) Measurements of diurnal variations in $\Psi$ and $\Psi_{S}$ in BJ 104 revealed osmotic adjustment during the afternoon hours. At a given value of $\Psi$, turgor $\left(\Psi_{\mathrm{P}}\right)$ was about $0.1 \mathrm{MPa}$ higher in irrigated, and over $0.2 \mathrm{MPa}$ higher in droughted plants, in the afternoon, than in the morning.

(3) Osmotic adjustment of different leaves within the canopy was investigated. Upper leaves had lower $\Psi$ than basal leaves. Differences in $\Psi$ were matched by gradients in $\Psi_{\mathrm{S}}$, so that turgor was similar for all leaf layers.

Key-words: Pennisetum americanum (L.) Leeke; Gramineae; pearl millet; osmotic adjustment; water stress.

\section{Introduction}

Osmotic adjustment has recently been recognized to be an important adaptive response to water stress in higher plants (Hsiao et al., 1976; Turner, 1979). An increase in cell solute content causing a decreased solute or osmotic potential $\left(\Psi_{\mathrm{S}}\right)$ is one means by which turgor potential $\left(\Psi_{\mathrm{P}}\right)$ is maintained despite a reduced total water potential $(\Psi)$. By maintaining

Correspondence: Dr I. E. Henson, Plant Breeding Institute, Maris Lane, Trumpington, Cambridge CB2 2LQ, England.

0140-7791/82/0400-0147\$02.00

(C) 1982 Blackwell Scientific Publications turgor high it is thought that osmotic adjustment enables processes such as stomatal opening, photosynthesis and cell expansion to continue at otherwise inhibitory water potentials (Turner, Begg \& Tonnet, 1978; Acevedo et al., 1979; Jones \& Rawson, 1979).

Active osmotic adjustment (as opposed to passive decreases in $\Psi_{\mathrm{S}}$ resulting from dehydration) has been demonstrated to occur in response to water stress in only a few species of crop plants, including maize (Hsiao et al., 1976; Fereres et al., 1978; Acevedo et al., 1979), sorghum (Hsiao et al., 1976; Fereres et al., 1978; Jones \& Turner, 1978; Stout \& Simpson, 1978; Turner et al., 1978; Acevedo et al., 1979; Jones \& Rawson, 1979; Ackerson, Kreig \& Sung, 1980), cotton (Cutler \& Rains, 1978), wheat (Morgan, 1977), sunflower (Turner et al., 1978; Jones \& Turner, 1980) and rice (Cutler, Shahan \& Steponkus, 1980).

In controlled environment cabinets, young plants of pearl millet (Pennisetum americanum [L.] Leeke) were found to adjust osmotically by 0.3 to $0.4 \mathrm{MPa}$ in response to leaf $\Psi$ falling to $-2.0 \mathrm{MPa}$ (Henson, 1982). The ability of pearl millet to adjust osmotically in the field has not previously been reported, although this plant is reputedly one of the most droughtresistant of the cereals (Ferraris, 1973). In the present study we examined osmotic adjustment in pearl millet in the field under conditions of high irradiance and evaporative demand in the semi-arid tropics.

\section{Materials and methods}

Field studies were conducted using crops established at ICRISAT Centre, near Hyderabad, Andhra Pradesh, India in the 1980 dry season (FebruaryMarch). The plants were grown in rows $0.75 \mathrm{~m}$ apart on slightly raised ridges on a deep $(c .90 \mathrm{~cm})$ alfisol soil. Seeds were direct sown in late January or early February and thinned subsequently to about $10 \mathrm{~cm}$ apart within the rows.

Three types of experiments were conducted. Experiment 1 was designed to determine seasonal trends in leaf water relations and to compare three cultivars, BJ 104, Serere 39, and B282, known to differ in their drought susceptibility, as measured by 
reduction in grain yields (ICRISAT, unpublished results). Two treatments were imposed. The control treatment was irrigated by flooding between the rows at approximately weekly intervals throughout crop life. For the drought treatment only two irrigations were given to ensure plant establishment, at sowing and $14 \mathrm{~d}$ later, after which time plant growth was almost entirely dependent upon residual soil moisture. The experiment was laid out as a split-plot design with three replications. Irrigation treatments were the main plots, and these were split for cultivars. Sub-plots were $4.5 \mathrm{~m}$ wide and $4.0 \mathrm{~m}$ long. Sampling was confined to the inner four of the six rows of each plot. Uppermost fully expanded leaves were sampled for water status measurements at approximately weekly intervals from the $22 \mathrm{nd}$ to the 60 th day after sowing, the control plants being sampled 3-4 d after irrigation. All sampling was done between 11.30 and $12.30 \mathrm{~h}$ Indian standard time when air temperatures were between $31^{\circ}$ and $36^{\circ} \mathrm{C}$, relative humidity was generally below $40 \%$ and energy fluence rate, as measured by a pyranometer sensor $(\lambda \simeq 300-3000 \mathrm{~nm})$, was about $700 \mathrm{~W} \mathrm{~m}^{-2}$.

In experiment 2 diurnal variations in leaf water potential components were measured on a crop of the cultivar BJ 104 sampled at approximately 60-90 min intervals throughout the photoperiod, from just before sunrise $(c .6 .00 \mathrm{~h})$ until after dusk $(c .19 .00 \mathrm{~h})$.

Plants were flowering when measurements were made ( $43 \mathrm{~d}$ after sowing). The penultimate leaf was selected, sampling being generally restricted to the main shoot.

Plants were grown either with regular furrow irrigation or with no further irrigation after the early vegetative phase, as in experiment 1.

In experiment 3 vertical gradients in $\Psi$ and its components were examined, again using the cultivar BJ 104. Plants were either fully irrigated or droughted as in the above experiments. A supplementary illumination (LD) treatment was superimposed on the irrigation treatments such that while half of each plot received only natural photoperiods $(c .11 .5-13 \mathrm{~h})$, the other half was given a $16 \mathrm{~h}$ photoperiod by extending the natural daylight with light from overhead incandescent lamps. This treatment substantially retarded flowering in BJ 104, a quantitative short day cultivar. Thus, at the time of sampling, 50-51 d after sowing, normal plants were in full flower while LD plants, although showing stem extension, had no emerged panicles, floral initiation having been delayed by about $18 \mathrm{~d}$. Leaves were sampled between 11.00 and $13.00 \mathrm{~h}$ at various positions on the plant, the uppermost leaves selected from flowering plants being the flag leaf, those from non-flowering plants being the youngest fully expanded leaves present.

\section{Methods of measuring leaf water status}

A pressure chamber was used to determine leaf water potential $(\Psi)$. Under the high evaporative conditions in the field it was essential to minimize post-excision evaporative losses. The leaf was therefore wrapped in a moist cloth just prior to excision, and the cloth was left in position during measurement of $\Psi$, so reducing errors in $\Psi$ determination arising from temperature increases during pressurization (Wenkert, Lemon \& Sinclair, 1978). If this procedure was not followed erroneously low values of $\Psi$ were obtained.

Expressed xylem sap of pearl millet had a solute potential $\left(\Psi_{\mathrm{S}}\right)$ of $-0.03 \mathrm{MPa}$ which could be neglected, and hence balance pressures were used directly as a measure of $\Psi$.

Following $\Psi$ measurement, sub-samples (half leaves, derived by longitudinal slitting of the leaf) were rapidly frozen by placing them in polythene envelopes and encasing between blocks of solid $\mathrm{CO}_{2}$. After temporary storage at below $-20^{\circ} \mathrm{C}$ the material was thawed at room temperature and the sap expressed using a hand press. Osmolality was determined on $100 \mathrm{~mm}^{3}$ sub-samples by freezing point depression using a Roebling micro-osmometer (Camlab Ltd., U.K.), and $\Psi_{\mathrm{S}}$ values were calculated taking into account variations in leaf temperature.

Leaf temperatures were measured either by a thermocouple attachment in the clip of a commercial diffusion porometer (Delta-T Devices, Burwell, U.K.), or in the case of diurnal studies (where large variations in leaf temperature occurred in the course of a day) by use of an infra-red thermometer (Barnes Engineering Co., Stamford, Connecticut, U.S.A.). This was frequently calibrated during operation using an insulated water bath, the temperature of which was measured with a mercury thermometer.

In experiment 1 measurements of $\Psi_{\mathrm{S}}$ were made also after rehydration of leaves to full turgidity. Leaves were excised at midday, weighed, placed with the cut ends in distilled water in sealed test tubes, and allowed to rehydrate over a period of $18-20 \mathrm{~h}$ at $c$. $20-25^{\circ} \mathrm{C}$ on the laboratory bench. The leaves were then split longitudinally, and one half was placed in a deep freeze, frozen, thawed, the sap expressed and $\Psi_{\mathrm{S}}$ determined as described above.

Turgor potential $\left(\Psi_{\mathrm{P}}\right)$ was derived as the difference between $\Psi$ and $\Psi_{\mathrm{S}}$ where:

$$
\Psi=\Psi_{\mathrm{S}}+\Psi_{\mathrm{P}}
$$

Relative water content (RWC) was determined on the remaining fully expanded leaf half as:

$$
\mathrm{RWC}=\frac{\text { fresh weight }- \text { dry weight }}{\text { turgid weight }- \text { dry weight }} \times 100
$$

Turgid weight was determined after rehydration in distilled water as described above, and dry weight after $24 \mathrm{~h}$ at $80^{\circ} \mathrm{C}$. A long incubation period was necessary to allow full rehydration of the most severely stressed samples. However, there was no indication of excessive water uptake during this period, and RWC of control leaves early in the season frequently exceeded $97 \%$. Similar RWC were 
obtained for control leaves using only short (4 h) incubation periods, and for control and stressed leaves using a pressure-volume technique (Henson, 1982). The latter method precludes certain sources of error potentially present during RWC determinations involving rehydration of excised tissues.

\section{Results}

\section{Seasonal osmotic adjustment}

The changes in mid-day $\Psi, \Psi_{\mathrm{S}}$ and $\Psi_{\mathrm{P}}$ of uppermost fully expanded leaves, encountered during the season are summarized in Fig. 1. As cultivars did not generally differ significantly in these variables only the mean values are presented.

For the fully irrigated treatment there was a decrease in $\Psi, \Psi_{\mathrm{S}}$, and $\Psi_{\mathrm{P}}$, the latter by $0.28 \mathrm{MPa}$, over the $35 \mathrm{~d}$ sampling period associated with increased evaporative demand and plant size. In the non-irrigated treatment there was a much greater
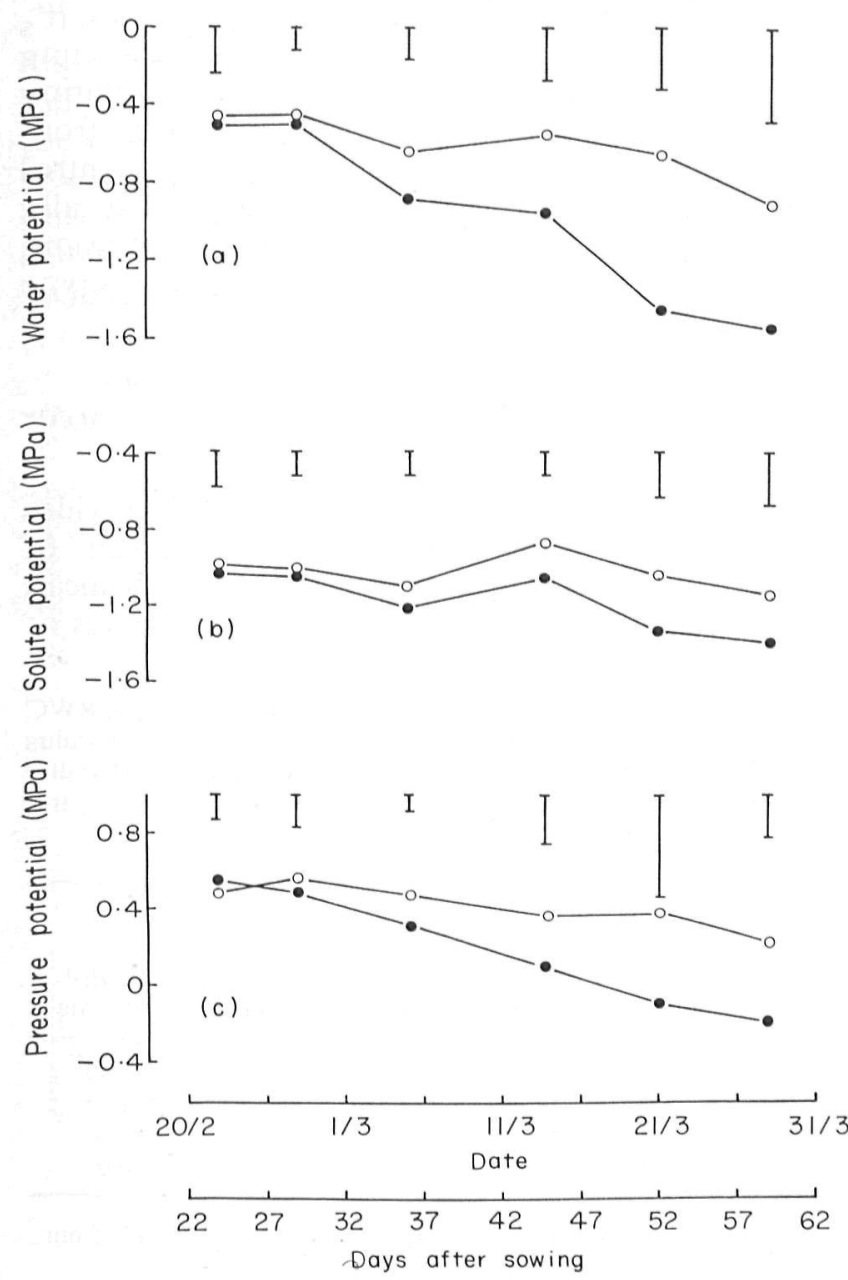

Figure 1. Seasonal changes in midday $\Psi$ (a), $\Psi_{\mathrm{S}}$ (b), and $\Psi_{\mathrm{P}}$ (c) of the uppermost fully expanded leaves of pearl millet grown in the field under irrigated $(O)$ and non-irrigated $(O)$ conditions. Data are means of three cultivars $(n=18)$. Vertical bars indicate LSD $(P=0.05)$ for comparing treatments. decline in $\Psi, \Psi_{\mathrm{S}}$ and $\Psi_{\mathrm{p}}$. The perturbation in $\Psi$ and $\Psi_{\mathrm{S}}$ at the fourth harvest was associated with $8.0 \mathrm{~mm}$ of unseasonal rainfall about $40 \mathrm{~h}$ preceding sampling. Despite these fluctuations in $\Psi$ and $\Psi_{\mathrm{S}}, \Psi_{\mathrm{P}}$ declined steadily by about $0.027 \mathrm{MPa} \mathrm{d} \mathrm{d}^{-1}$ between $27 / 2$ and $21 / 3$ becoming negative after $18 / 3$. Thus, while loss of turgor was not avoided, its rate of decrease was more constant than that of $\Psi$. It is not possible to determine from simple inspection of these data whether turgor loss was minimized as a result of osmotic adjustment. To determine the extent of adjustment three procedures were followed.

(i) Regression lines of $\Psi_{\mathrm{P}}$ on $\Psi$ were calculated for each cultivar. Although, as $\Psi_{\mathrm{P}}=\Psi-\Psi_{\mathrm{S}}$, a close relationship is to be expected between $\Psi_{\mathrm{P}}$ and $\Psi$, the lines were fitted in order to obtain values for $\Psi$ at zero $\Psi_{\mathrm{P}}$ and for the rate of decrease in $\Psi_{\mathrm{P}}$ per MPa decline in $\Psi$ ('observed' values, Table 1). While, as shown by individual $t$-tests, there was no significant difference between genotypes in the intercept (the value of $\Psi_{\mathrm{P}}$ at zero $\Psi)$, the slope for BJ 104 was significantly $(P=<0.01)$ less steep than that for Serere 39. The slope of B282 did not differ significantly from slopes of either of the other cultivars.

Theoretical slopes were calculated for each genotype assuming that only 'passive' increases in solute concentration occurred in proportion to the loss of water during stress ('predicted' values, Table 1). A procedure similar to that outlined by Smith \& Milburn (1980) was followed which involved the fixing of two co-ordinates:

(a) the value of $\Psi$ at 'maximum observed' $\Psi_{\mathrm{p}}$. For this purpose the mean $\Psi$ and $\Psi_{\mathrm{P}}$ obtained for each genotype on the first sampling occasion were designated as 'maximum observed' values. These points lay on the fitted line for Serere 39 and B282 and within $0.01 \mathrm{MPa}$ of it for BJ 104. From the mean $\Psi$ and mean $\Psi_{\mathrm{P}}$ the solute potential, $\Psi_{\mathrm{S}}$, could be calculated, viz $\Psi_{\mathrm{S}}=\Psi-\Psi_{\mathrm{P}}$.

Table 1. Predicted and observed relationships between $\Psi_{P}$ and $\Psi$ of uppermost fully expanded leaves of three cultivars of pearl millet. Data derived from midday values obtained over a 6 week period from both irrigated and non-irrigated plots $(n=72)$. Observed values were derived from linear regressions of $\Psi_{\mathrm{P}}$ on $\Psi$ (where $\left.\Psi_{\mathrm{P}}=\alpha-\beta \Psi\right)$. Predicted values were calculated as described in the text. Differences between these values are a measure of osmotic adjustment. Potentials are given in $\mathrm{MPa}$

\begin{tabular}{lccc}
\hline & \multicolumn{3}{c}{ Cultivar } \\
\cline { 2 - 4 } & BJ 104 & Serere 39 & B282 \\
\hline$\Psi$ at zero $\Psi_{\mathrm{P}}:$ & & & \\
observed & 1.44 & 1.16 & 1.25 \\
predicted & 1.22 & 1.05 & 1.13 \\
difference & 0.22 & 0.11 & 0.12 \\
$\Delta \Psi_{\mathrm{P}} / \Delta \Psi(\beta):$ & $0.58 \pm 0.04$ & $0.72 \pm 0.03$ & $0.68 \pm 0.04$ \\
observed $( \pm$ s.e. $)$ & 0.78 & 0.88 & 0.81 \\
predicted & 0.20 & 0.16 & 0.13 \\
difference & & & \\
$\%$ variance accounted for & 77.6 & 87.3 & 83.6 \\
by regression of $\Psi_{\mathrm{P}}$ on $\Psi$ & &
\end{tabular}


Table 2. Observed and predicted changes in $\Psi_{S}(\mathrm{MPa})$ at midday in the uppermost fully expanded leaves of pearl millet over a 5 week period. Predicted values are those expected if $\Psi_{S}$ decreased due to water loss only and are calculated using the appropriate observed values of mean RWC. $\Delta \Psi_{\mathrm{S}}$ equals difference between predicted and observed values. Data are means of all cultivars \pm s.e.; $n=18$

\begin{tabular}{|c|c|c|c|c|c|c|}
\hline \multirow[b]{3}{*}{ Treatment } & \multicolumn{5}{|c|}{ Days after sowing } & \\
\hline & \multicolumn{2}{|c|}{29} & \multicolumn{4}{|c|}{59} \\
\hline & RWC $(\%)$ & observed $\Psi_{\mathrm{S}}$ & RWC $(\%)$ & observed $\Psi_{\mathrm{S}}$ & predicted $\Psi_{\mathrm{S}}$ & $\Delta \Psi_{\mathrm{S}}$ \\
\hline Control & $97.1 \pm 0.28$ & $-1.02 \pm 0.026$ & $95.6 \pm 0.68$ & $-1.16 \pm 0.032$ & -1.04 & -0.12 \\
\hline Droughted & $95.6 \pm 0.94$ & $-1.03 \pm 0.019$ & $86.5 \pm 1.06$ & $-1.39 \pm 0.034$ & -1.14 & -0.25 \\
\hline
\end{tabular}

(b) the value of $\Psi$ at $\Psi_{\mathrm{P}}=$ zero. At zero $\Psi_{\mathrm{P}}, \Psi=\Psi_{\mathrm{S}}$. The $\Psi_{\mathrm{S}}$ at zero turgor $\left(\Psi_{\mathrm{S}_{\mathrm{z}}}\right)$ was calculated from the values of $\Psi_{\mathrm{S}}$ at 'maximum observed' $\Psi_{\mathrm{P}}$, and from the change in RWC between this point and zero turgor, according to the relation:

$$
\Psi_{\mathrm{S}_{\mathrm{zt}}}=\left(\Psi_{\mathrm{S}_{\mathrm{m}}} \times \mathrm{RWC}_{\mathrm{m}}\right) / \mathrm{RWC}_{\mathrm{zt}}
$$

where the subscripts $\mathrm{m}$ and $\mathrm{zt}$ indicate the value at 'maximum observed' and zero $\Psi_{\mathrm{P}}$ respectively, and $\mathrm{RWC}_{\mathrm{zt}}$ was derived from linear regression of $\Psi_{\mathrm{P}}$ on RWC.

For BJ 104, from the line fitted to the experimental data, $\Psi_{\mathrm{P}}$ decreased by $0.58 \mathrm{MPa}$ for each $\mathrm{MPa}$ decrease in $\Psi$ while the predicted rate was $0.78 \mathrm{MPa}$ $\Psi_{\mathrm{P}} \mathrm{MPa}^{-1} \Psi$ (Table 1). Differences between observed and predicted slopes were 2.3, 3.5 and 3.5 times the standard error for the differences (calculated assuming a similar coefficient of variation for both slopes) for B282, Serere 39, and BJ 104, respectively. The observed $\Psi$ at which $\Psi_{\mathrm{P}}$ became zero, was, depending on genotype, c. $0.1-0.2 \mathrm{MPa}$ lower than predicted values (Table 1 ).

(ii) To calculate the extent of osmotic adjustment over the season for the individual treatments, the mean $\Psi_{S}$ per treatment on the last sampling date was compared with that predicted-calculated as in (i) above-taking into account initial values of $\Psi_{\mathrm{S}}$ and

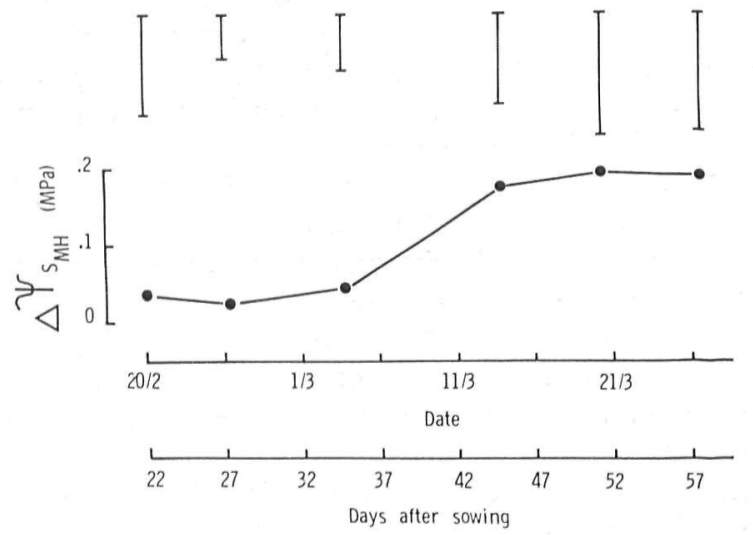

Figure 2. Changes over the season in the difference in $\Psi_{\mathrm{S}}$ measured at maximum hydration $\left(\Psi_{\mathrm{S}_{\mathrm{MH}}}\right)$ between leaves from irrigated and non-irrigated plots of pearl millet. Each point represents the mean difference $\left(\Delta \Psi_{\mathrm{S}_{\mathrm{MH}}}=\Psi_{\mathrm{S}_{\mathrm{MH}}}\right.$ irrigated $-\Psi_{\mathrm{S}_{\mathrm{MH}}}$ non-irrigated) for all cultivars $(n=9)$. The vertical bars represent the least difference required for significance at $P=0.05$. seasonal changes in RWC. This assessment (Table 2) showed that a small degree of adjustment occurred in the control, as well as the droughted, treatment.

(iii) Further evidence of osmotic adjustment during the season was obtained by comparing $\Psi_{\mathrm{S}}$ of leaves from control and droughted plots after rehydration to full turgor (see Materials and methods). The difference in $\Psi_{\mathrm{S}}$ at maximum hydration $\left(\Psi_{\mathrm{S}_{\mathrm{MH}}}\right)$ between control and droughted treatments serves as a direct measure of the effect of drought on $\Psi_{\mathrm{S}}$ independent of current tissue water content assuming no major change occurs in solute mass during rehydration. As anticipated, $\Psi_{\mathrm{S}_{\mathrm{MH}}}$ of leaves from droughted plots was always less than $\Psi_{\mathrm{S}_{\mathrm{MH}}}$ of control leaves (Fig. 2), the difference becoming statistically significant $(P<0.05)$ by the fourth sampling occasion. There were no significant treatment $\times$ genotype interactions.

\section{Contribution of cell wall elasticity to turgor maintenance}

An increase in the elasticity of the cell wall provides an alternative means to osmotic adjustment of maintaining $\Psi_{\mathrm{P}}$ as $\Psi$ decreases. Estimates of the mean seasonal volumetric elastic modulus $(\varepsilon)$ for leaves at

Table 3. $\Psi_{\mathrm{S}}$ at full hydration $\left(\Psi_{\mathrm{S}_{\mathrm{MH}}}\right), \Psi_{\mathrm{S}}$ at zero turgor $\left(\Psi_{\mathrm{S}_{\mathrm{zt}}}\right)$, RWC at zero turgor $\left(\mathrm{RWC}_{\mathrm{zt}}\right)$, and the bulk volumetric elastic modulus (E), for uppermost fully expanded leaves of three pearl millet cultivars. Values are derived from midday sampling for $\Psi, \Psi_{\mathrm{S}}$ and RWC

\begin{tabular}{lccccc}
\hline & & \multicolumn{3}{c}{ Cultivar } & \\
\cline { 3 - 5 } & & & & \\
& & BJ 104 & Pooled \\
& & Serere 39 & B282 & estimate \\
\hline$* \Psi_{\mathrm{S}_{\mathrm{MH}}}$ & $(\mathrm{MPa})$ & -1.22 & -1.05 & -1.06 & -1.11 \\
$\dagger \Psi_{\mathrm{S}_{\mathrm{z}}}$ & $(\mathrm{MPa})$ & -1.44 & -1.16 & -1.25 & -1.28 \\
$\$ \mathrm{RWC}_{\mathrm{zt}}$ & $(\%)$ & 84.4 & 90.3 & 85.0 & 87.0 \\
$\S \varepsilon$ & $(\mathrm{MPa})$ & 7.8 & 10.8 & 7.1 & 8.6 \\
\hline
\end{tabular}

* Equals $\Psi_{\mathrm{P}}$ at maximum hydration and was calculated from: $\Psi_{\mathrm{S}_{\mathrm{zt}}} \times\left(\mathrm{RWC}_{\mathrm{zt}} / 100\right)$.

$\dagger$ Derived by linear regression of $\Psi_{\mathrm{P}}$ on $\Psi$.

† Derived by linear regression of $\Psi_{\mathrm{P}}$ on RWC.

$\S$ Calculated as: $\left[\Psi_{\mathrm{P}_{\mathrm{MH}}} /\left(100-\mathrm{RWC}_{\mathrm{zt}}\right)\right] \times 100$. $=\left(\Delta \Psi_{\mathrm{P}} / \Delta \mathrm{RWC}\right) \times 100($ Jones \& Turner, 1978) . $\Psi_{\mathrm{P}_{\mathrm{MH}}}=\Psi_{\mathrm{P}}$ at maximum hydration. 
zero $\Psi_{\mathrm{P}}$ in the field, for the three cultivars included in the above experiment, are presented in Table 3 . The value of $\varepsilon$ for $\mathrm{BJ} 104$ is close to those obtained previously $(7.3-8.9 \mathrm{MPa})$ for plants grown with ample water supply in a growth cabinet (Henson, 1982; unpublished results). Thus, for this cultivar there may be little change in $\varepsilon$ arising from a change in environment. In Serere 39, however, $\varepsilon$ was estimated to be $10.8 \mathrm{MPa}$ in the field compared with previous estimates for well watered pot-grown plants of 5.6-8.4 MPa; thus, mean elasticity was less in fieldgrown plants.

\section{Diurnal osmotic adjustment}

Diurnal variations in total water potential are well documented. However, Hsiao and co-workers (Hsiao et al., 1976; Acevedo et al., 1979) demonstrated that in maize and sorghum $\Psi_{S}$ also varied diurnally, maintaining turgor positive and relatively constant for a large part of the day despite considerable variation in $\Psi$.

Diurnal measurements of $\Psi$ and $\Psi_{S}$ in both irrigated and droughted plots of pearl millet (cultivar BJ 104) indicated a capacity for osmotic adjustment during the course of a day. While both $\Psi$ and $\Psi_{\mathrm{S}}$ declined from high values at dawn to a minimum at midday, only $\Psi$ underwent a corresponding increase in the afternoon; the recovery in $\Psi_{\mathrm{S}}$ being only partial (Fig. $3 \mathrm{a}, \mathrm{b})$. Hence $\Psi_{\mathrm{P}}$ at a given value of $\Psi$ was greater in
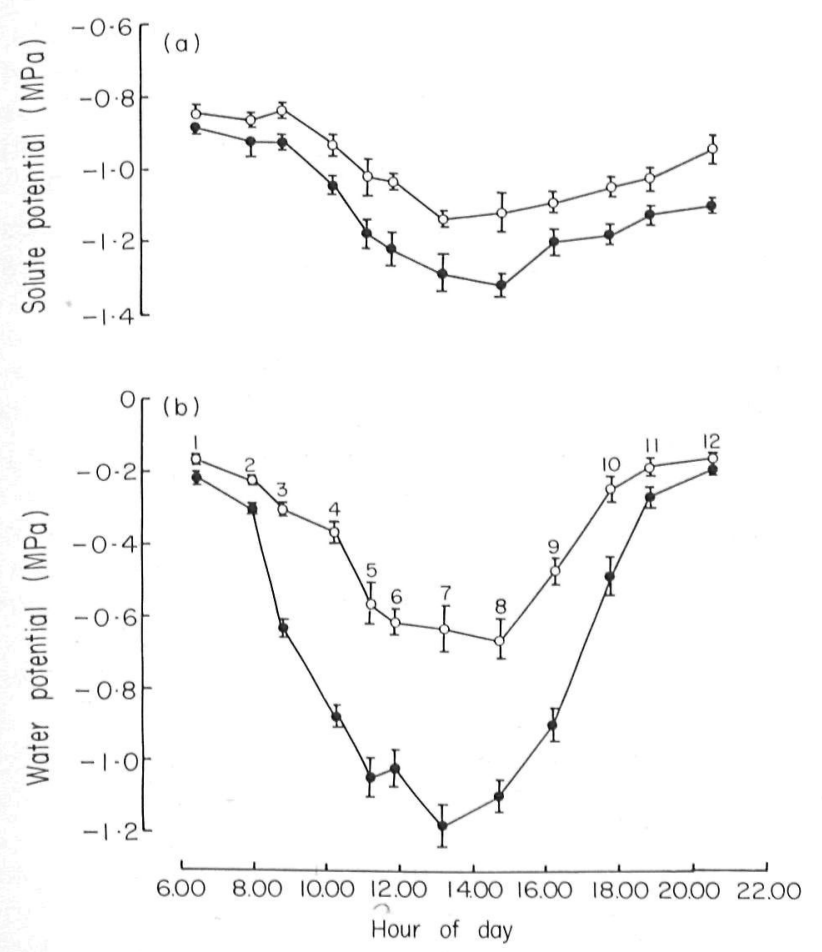

Figure 3. Changes during the course of a single photoperiod $(19 / 3 / 80)$ in $\Psi_{\mathrm{S}}($ a) and $\Psi$ (b) of upper, fully expanded leaves of BJ 104 grown with $(\bigcirc)$ or without $(\bullet)$ regular irrigation. Vertical bars indicate \pm s.e. and $n=6$. Sampling times are numbered $1-12$ (see Fig. 4).

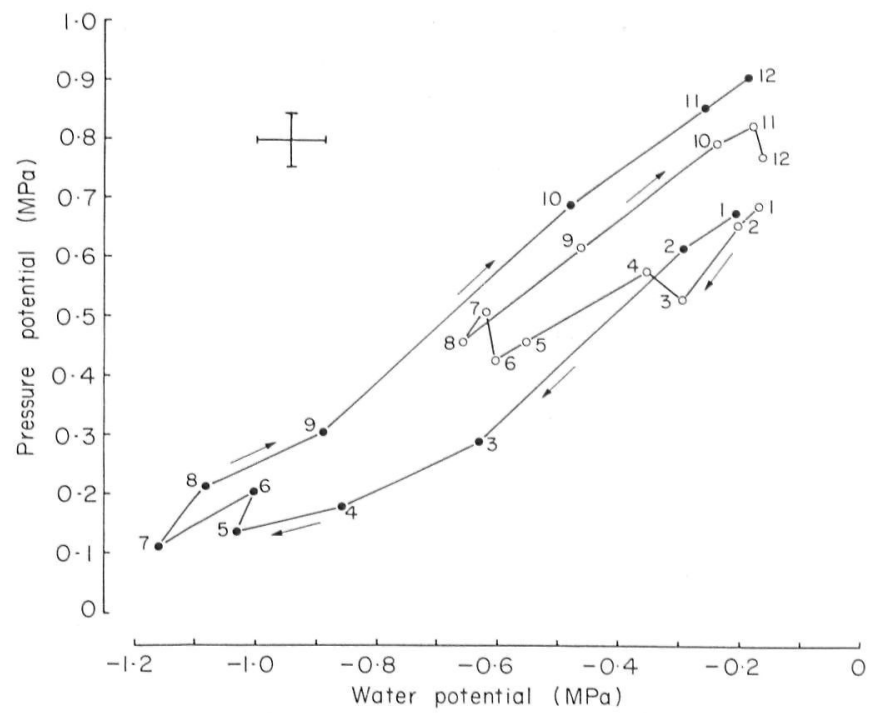

Figure 4. The relationship between $\Psi_{\mathrm{P}}$ and $\Psi$ of upper, fully expanded leaves of BJ 104 grown with $(\bigcirc)$ or without $(\mathcal{O})$ regular irrigation, and sampled throughout the course of a single photoperiod (19/3/80). Arrows indicate the direction of change and numbers indicate the sampling times as shown in Fig. 3. Bars indicate least significant difference for comparing any two points $(P=0.05)$.

the afternoon compared with the morning. This accords with data for maize (Hsiao et al., 1976). A plot of $\Psi_{\mathrm{P}}$ vs $\Psi$ (Fig. 4) for the data in Fig. 3 shows that at a given $\Psi, \Psi_{\mathrm{P}}$ is maintained about $0.25 \mathrm{MPa}$ higher after midday than before it for a droughted treatment, and about 0.1 MPa higher for the control.

\section{Vertical gradients in leaf water potential components in the canopy}

In the foregoing field experiments sampling was restricted to the uppermost leaves. However, leaves at different levels up the plant may be at different water potentials, and vertical gradients in $\Psi, \Psi_{\mathrm{S}}$ and $\Psi_{\mathrm{P}}$ may occur (Turner \& Begg, 1973; Turner, 1974; Hsiao et al., 1976), being associated with gradients in leaf conductance $\left(\mathrm{g}_{\mathrm{l}}\right)$ and micro climate (Begg et al., 1964; Turner \& Begg, 1973; Turner, 1974; Sivakumar et al., 1979; Squire, 1979).

Vertical profiles of water potential components for irrigated and droughted stands of pearl millet, BJ 104, are shown in Fig. 5. For irrigated, flowering plants flag leaf $\Psi$ was $0.4 \mathrm{MPa}$ lower than $\Psi$ of the lowest leaf. This gradient in $\Psi$ was almost exactly matched by a corresponding gradient in $\Psi_{S}$, maintaining a positive value of $\Psi_{\mathrm{P}}$ which was almost equal in all leaves. The 'vegetative' plants showed a similar trend, although the gradients were smaller. Similar results were obtained from droughted plants. (It was not, however, possible to obtain reliable estimates of $\Psi$ of the flag leaves of stressed plants due to fracture of the laminae in the pressure chamber at the high pressures required to expel sap.) In stressed plants $\Psi$ was usually lower than $\Psi_{S}$, giving 'negative' values for $\Psi_{P}$. 


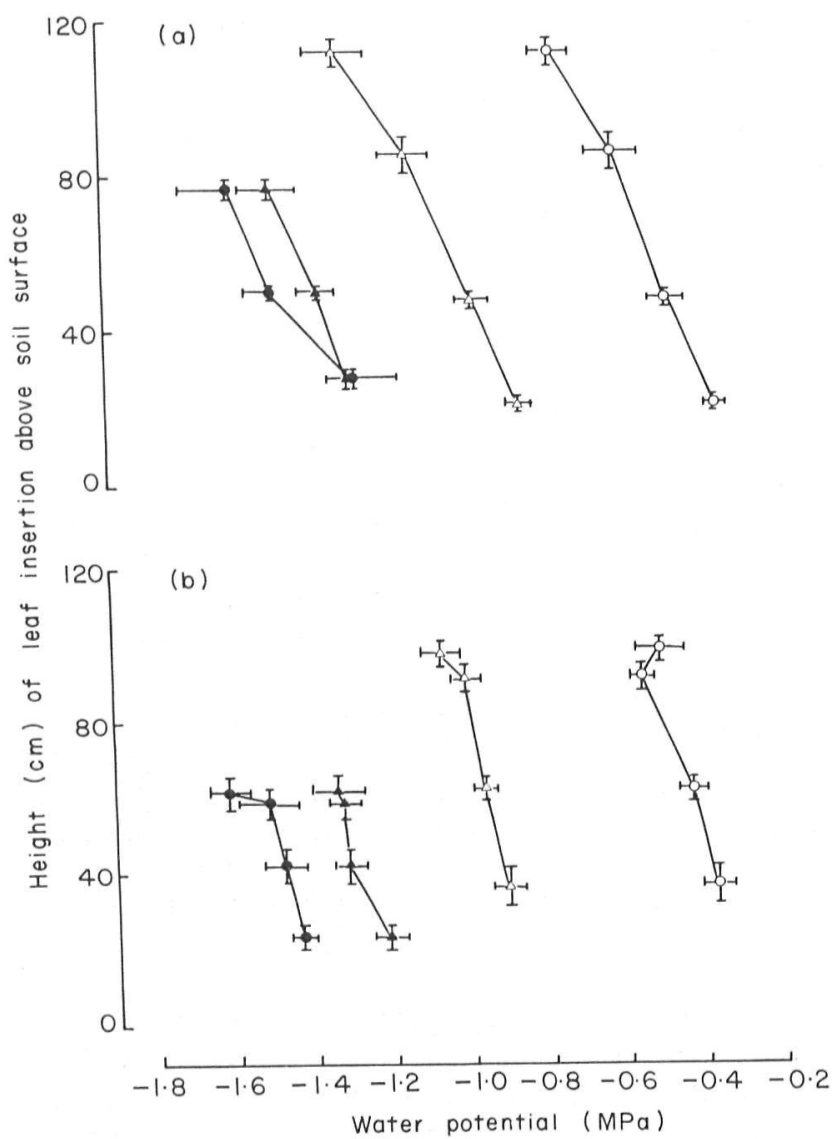

Figure 5. Vertical gradients in $\Psi(\bigcirc, \bullet)$ and $\Psi_{\mathrm{S}}(\triangle, \boldsymbol{\Delta})$ in irrigated $(\bigcirc, \triangle)$ and non-irrigated $(\boldsymbol{O}, \boldsymbol{\Delta})$ stands of pearl millet BJ 104 at midday: (a) flowering plants, (b) 'vegetative' plants. Bars indicate \pm s.e.; $n=6$.

\section{Discussion}

Recently there has been considerable interest in osmotic adjustment as an adaptive response to water stress by higher plants (Hsiao et al., 1976; Turner, 1979). An 'active' increase in the concentration of cell solutes permits a positive turgor potential to be maintained at lower values of water potential than would be possible if the solute concentration were to increase solely as a result of tissue water loss.

In the present study there was evidence for active osmotic adjustment by pearl millet in response to water stress. However, the adjustment was only $c$. $0.1-0.3 \mathrm{MPa}$, depending on the method of assessment and the basis used for comparisons. A similar degree of adjustment was observed for young potted millet plants grown in a controlled environment cabinet (Henson, 1982), and is less than that of several other crop species (Table 4). However, when allowance is made for 'initial' solute contents (i.e. $\Psi_{\mathrm{S}}$ at maximum hydration) and the relative decrease in $\Psi_{\mathrm{S}}$ is used as the basis for comparison, the extent of adjustment is similar for most of the species. Osmotic adjustment in millet was inadequate to sustain high turgor at midday and to prevent the gradual reduction in $\Psi_{\mathrm{P}}$ to 'negative' values in the absence of sufficient soil moisture.

Measurements of osmotic potential were obtained in the present study using expressed sap. It is generally recognized (e.g. Fereres et al., 1978; Jones \& Turner, 1978, Turner et al., 1978; Wenkert, 1980) that, largely owing to dilution of symplastic solutes with apoplastic water, this technique results in an overestimation of $\Psi_{S}$, and hence an underestimation of $\Psi_{p}$. In a recent study, the error for sorghum arising from this cause, and considered to account for the negative values of $\Psi_{\mathrm{p}}$ obtained, was in the order of $0.4 \mathrm{MPa}$ (Turner et al., 1978). The extent of the error will, however, depend on the magnitude of $\Psi_{\mathrm{S}}$ as well as on other factors as discussed by Wenkert (1980).

For pot-grown millet, comparisons between values of $\Psi_{\mathrm{S}}$ obtained using expressed sap, and $\Psi_{\mathrm{S}}$ values

Table 4. Comparison of (i) $\Psi_{S}$ at maximum hydration in non-stressed plants $\left(\Psi_{\mathrm{S}_{\mathrm{MH}}}=\Psi_{\mathrm{P}}\right.$ at maximum hydration, but of opposite sign), (ii) the decrease in $\Psi_{\mathrm{S}}$ in stressed plants attributable to active osmotic adjustment $\left(\Delta \Psi_{\mathrm{S}}\right)$, and (iii) the relative osmotic adjustment $\left(\Delta \Psi_{\mathrm{S}} / \Psi_{\mathrm{S}_{\mathrm{MH}}} \times 100\right)$ for leaves of several crop species

\begin{tabular}{|c|c|c|c|c|}
\hline Species & $\begin{array}{l}\Psi_{\mathrm{SMH}} \\
(\mathrm{MPa})\end{array}$ & $\begin{array}{c}\Delta \Psi_{\mathrm{S}} \\
(\mathrm{MPa})\end{array}$ & $\begin{array}{c}\text { Relative } \\
\text { adjustment } \\
(\%)\end{array}$ & Reference \\
\hline Pearl millet & -0.81 & 0.36 & 44 & Henson (1982) \\
\hline$", \quad " \quad \S$ & -0.98 & 0.25 & 26 & This paper (Table 2 ) \\
\hline$", \quad "+\Phi$ & $\simeq-0.84$ & $\simeq 0.25$ & $\simeq 30$ & $" \quad, \quad$ (Fig. 4) \\
\hline Sorghum* & -0.70 & 0.90 & 129 & Jones \& Turner (1978) \\
\hline$" \quad+$ & $\simeq-1.00$ & $\simeq 0.40$ & $\simeq 40$ & Acevedo et al. (1979) \\
\hline Maize† & $\simeq-1.00$ & $\simeq 0.40$ & $\simeq 40$ & $" \quad " \quad "(")$ \\
\hline Rice & $\simeq-1.30$ & $\simeq 0.50$ & $\simeq 38$ & Cutler et al. (1980) \\
\hline Wheat $\$ \S$ & $\simeq-1.50$ & $\simeq 1.50$ & $\simeq 100$ & Morgan (1977) \\
\hline Cotton & -1.16 & 0.56 & 48 & Pierce \& Raschke (1980) \\
\hline
\end{tabular}

* means for two cultivars.

$\dagger$ diurnal change.

\$ certain genotypes only.

$\S$ data derived by extrapolation of values obtained during slow drying treatment.

I derived by extrapolation of $\Psi_{\mathrm{P}}$ vs $\Psi$ to zero $\Psi$. 
obtained with 'pressure-volume' techniques, generally showed good agreement (Henson, 1982), indicating only a small dilution error in the former technique. It is, however, probable that errors arising from dilution with apoplastic water were greater in the field-grown material (which had a higher dry weight content and hence potentially increased apoplast volume). Firm conclusions regarding the extent of error introduced by neglecting effects of the apoplast cannot be made, due to uncertainties regarding apoplast volume, and degree of mixing during sap extraction (Wenkert, 1980). The degree of adjustment detected in the present study should, therefore, be considered to be a minimum estimate in accordance with the arguments put forward, e.g., by Fereres et al. (1978). Nevertheless, the degree of osmotic adjustment in pearl millet would appear to be small, especially when compared with sorghum (Table 4 ), another $\mathrm{C}_{4}$ cereal for which similar techniques for measuring $\Psi_{S}$ were used to assess osmotic adjustment (Jones \& Turner, 1978; Turner et al., 1978; Fereres et al., 1978).

An increase in cell wall elasticity is another mechanism by which turgor may be maintained despite water loss (Turner, 1979). However, this factor seems unlikely to have contributed greatly to turgor maintenance in millet. Estimates of $\varepsilon$ (the mean volumetric elastic modulus) for BJ 104 were similar for both droughted, field-grown, and well-watered laboratory-grown plants, while for Serere $39, \varepsilon$ of field-grown plants was greater than that of plants raised in growth cabinets, i.e. elasticity was less under field conditions.

Osmotic adjustment on a seasonal basis could have arisen partly from effects of water stress on leaf development, via a reduction in cell size (Cutler, Rains \& Loomis, 1977). That osmotic adjustment did not arise solely as a result of developmental changes was, however, suggested by the rapid diurnal adjustments which occurred (Figs 3 \& 4). The relationship between $\Psi_{\mathrm{P}}$ and $\Psi$ underwent a distinct shift following the attainment of minimum $\Psi$ at midday (Fig. 4). The extent of the osmotic shift appeared to be related to the minimum $\Psi$ (or $\Psi_{\mathrm{P}}$ ) attained. By extrapolation of those portions of the curves in Fig. 4 relating $\Psi_{\mathrm{p}}$ to $\Psi$ in the morning and afternoon respectively, it is possible to estimate the mean $\Psi_{\mathrm{P}}$ (and hence $\Psi_{\mathrm{S}}$ ) at full hydration (zero $\Psi$ ) for these periods. For the stressed treatment the difference in $\Psi_{\mathrm{S}}$ between the two times (c. $0.25 \mathrm{MPa}$ ) was of a similar order to the maximum seasonal adjustment recorded. The significance of the higher afternoon turgor potentials is not presently clear. Contrary to expectations, the increase in turgor did not result in stomatal opening in pearl millet, as under field conditions $\mathrm{g}_{\mathrm{l}}$ was mainly determined by energy fluence rate (irradiance) (Henson et al., 1982), and both energy fluence rate and stomatal conductance declined at the time that $\Psi_{\mathrm{P}}$ increased. It is likely that leaf extension would be favoured at this time of high turgor, and would benefit also from high substrate levels accumulated during the morning period when stomata were open and when low turgor may have inhibited growth. Frequent measurements of leaf growth over the course of a day in maize and sorghum (Acevedo et al., 1979) show a late afternoon peak in elongation rate, while elongation measurements in pearl millet on a daily basis (results not presented) indicated that quite appreciable extension growth occurred in plants with zero or 'negative' turgor at midday.

Vertical gradients in $\Psi_{S}$ and $\Psi$ in BJ 104 indicated that osmotic adjustment between leaf layers $(\simeq 0.4 \mathrm{MPa})$ may have been greater than either seasonal or diurnal variation within a single leaf layer. Probably both positional and ontogenetic factors contributed to these gradients. The maintenance of almost constant $\Psi_{\mathrm{P}}$ despite the decline (c. $0.4 \mathrm{MPa}$ ) in $\Psi$ up to canopy must have resulted very largely from differential solute accumulation, in view of only minimal changes with environment in cell wall elasticity in this cultivar. The $0.44 \mathrm{MPa}$ decrease in $\Psi_{\mathrm{S}}$ in irrigated flowering plants represents c. $50 \%$ increase in concentration over the solutes present in the lower leaf layer sampled. This could only have occurred passively if the tissue water content had decreased by $34 \%$, well below the point expected for zero turgor (Table 3). The lower $\Psi$ and $\Psi_{S}$ of upper leaves were associated with higher values of stomatal conductance (Henson et al., 1982). This is as expected due to the decrease in light interception down the canopy (Begg et al., 1964) and the influence of energy fluence rate on stomatal aperture (Squire, 1979; Henson et al., 1982). Higher assimilation rates expected of upper leaves would serve to maintain low $\Psi_{S}$. (Gradients in vapour pressure deficit may, however, have contributed additionally to the gradients in $\Psi$ ).

In the seasonal study there was evidence (Table 1) that cultivars differed in the ability to osmotically adjust. BJ 104 showed a greater degree of adjustment than Serere 39. This difference has been confirmed in experiments with pot-grown plants (Henson, 1982). In the field Serere 39 attained zero turgor at higher RWC than either BJ 104 or B282 (Table 3), and had a lower cell wall elasticity than those cultivars.

To summarize, both the present results, and those of another investigation (Henson, 1982), show that pearl millet has the capacity to adjust osmotically in response to water stress. The extent of adjustment observed is likely to have been underestimated here due to the method of measuring $\Psi_{S}$, but a similar degree of adjustment and comparable genotypic differences have also been observed using an alternative technique (Henson, 1982). Also the 'relative' capacity for such adjustment (Table 4) appears to be similar to that of some other crop species for which data are available, with the exceptions of sorghum and certain wheat genotypes. Whether the capacity of pearl millet to adapt osmotically in response to water stress is expressed 
more strongly in other environments or in genotypes other than those tested, or whether it is an unimportant factor in the adaptation of the crop to stress environments are questions which demand further investigation.

\section{Acknowledgments}

We are most grateful to R. B. Austin, P. Innes, D. W. Lawlor and S. A. Quarrie for their critical comments on the manuscript. We should like to thank G. D. Prasada Rao for his help with data analysis, and members of the staff of the millet physiology section at ICRISAT for their assistance with the field experiments. I.E.H. is grateful to the UK Overseas Development Administration for financial support and for the provision of funds to visit ICRISAT.

\section{References}

Acevedo, E., Fereres, E., Hsiao, T.C. \& Henderson, D.W. (1979) Diurnal growth trends, water potential, and osmotic adjustment of maize and sorghum leaves in the field. Plant Physiology, 64, 476-480.

Ackerson, R.C., Krieg, D.R. \& Sung, F.J.M. (1980) Leaf conductance and osmoregulation of field-grown sorghum genotypes. Crop Science, 20, 10-14.

Begg, J.E., Bierhuizen, J.F., Lemon, E.R., Misra, D.K., Slatyer, R.D. \& Stern, W.R. (1964) Diurnal energy and water exchanges in bulrush millet in an area of high solar radiation. Agricultural Meteorology, 1, 294-312.

Cutler, J.M. \& Rains, D.W. (1978) Effects of water stress and hardening on the internal water relations and osmotic constituents of cotton leaves. Physiologia Plantarum, 42, 261-268.

Cutler, J.M., Rains, D.W. \& Loomis, R.S. (1977) The importance of cell size in the water relations of plants. Physiologia Plantarum, 40, 255-260.

Cutler, J.M., Shahan, K.W. \& Steponkus, P.L. (1980) Alteration of the internal water relations of rice in response to drought hardening. Crop Science, 20, 307-310.

Fereres, E., Acevedo, E., Henderson, D.W. \& Hsiao, T.C. (1978) Seasonal changes in water potential and turgor maintenance in sorghum and maize under water stress. Physiologia Plantarum. 44, 261-267.

Ferraris, R. (1973) Pearl millet (Pennisetum typhoides). Review Series 1/1973, Commonwealth Agricultural Bureaux 70p.

Henson, I.E. (1982) Osmotic adjustment to water stress in pearl millet (Pennisetum americanum [L.] Leeke) in a controlled environment. Journal of Experimental Botany 33, (in press).
Henson, I.E., Alagarswamy, G., Bidinger, F.R. \& Mahalakshmi, V. (1982) Stomatal responses of pearl millet (Pennisetum americanum [L.] Leeke) to leaf water status and environmental factors in the field. Plant, Cell and Environment, 5, 65-74.

Hsiao, T.C., Acevedo, E., Fereres, E. \& Henderson, D.W. (1976) Water stress, growth, and osmotic adjustment. Philosophical Transactions of the Royal Society, London, Series B, 273, 479-500.

Jones, M.M. \& Rawson, H.M. (1979) Influence of rate of development of leaf water deficits upon photosynthesis, leaf conductance, water use efficiency, and osmotic potential in sorghum. Physiologia Plantarum, 45, 103-111.

Jones, M.M. \& Turner, N.C. (1978) Osmotic adjustment in leaves of sorghum in response to water deficits. Plant Physiology, 61, $122-126$

Jones, M.M. \& Turner, N.C. (1980) Osmotic adjustment in expanding and fully expanded leaves of sunflower in response to water deficits. Australian Journal of Plant Physiology, 7, 181-192.

Morgan, J. M. (1977) Differences in osmoregulation between wheat genotypes. Nature, 270, $234-235$.

Pierce, M. \& Raschke, K. (1980) Correlation between loss of turgor and accumulation of abscisic acid in detached leaves. Planta, 148, $174-182$.

Sivakumar, M.V.K., Seetharama, N., Singh, S. \& Bidinger, F.R. (1979) Water relations, growth, and dry matter accumulation of sorghum under post-rainy season conditions. Agronomy Journal, 71, 843-847.

Smith, J.A.C. \& Milburn, J.A. (1980) Phloem turgor and the regulation of sucrose loading in Ricinus communis L. Planta, 148, 42-48.

Squire, G.R. (1979) The response of stomata of pearl millet (Pennisetum typhoides S. and $\mathrm{H}$.) to atmospheric humidity. Journal of Experimental Botany, 30, 925-933.

Stout, D.G. \& Simpson, G.M. (1978) Drought resistance of Sorghum bicolor. I. Drought avoidance mechanisms related to leaf water status. Canadian Journal of Plant Science, 58, 213-224.

Turner, N.C. (1974) Stomatal behaviour and water status of maize, sorghum, and tobacco under field conditions. II. At low soil water potential. Plant Physiology, 53, 360-365.

Turner, N.C. (1979) Drought resistance and adaptation to water deficits in crop plants. In Stress Physiology in Crop Plants (eds H. Mussell \& R.C. Staples), pp. 343-372. Wiley-Interscience, New York.

Turner, N.C. \& Begg, J.E. (1973) Stomatal behaviour and water status of maize, sorghum, and tobacco under field conditions. I. At high soil water potential. Plant Physiology, 51, 31-36.

Turner, N.C., Begg, J.E. \& Tonnet, M.L. (1978) Osmotic adjustment of sorghum and sunflower crops in response to water deficits and its influence on the water potential at which stomata close. Australian Journal of Plant Physiology, 5, 597-609.

Wenkert, W. (1980) Measurement of tissue osmotic pressure. Plant Physiology, 65, 614-617.

Wenkert, W., Lemon, E.R. \& Sinclair, T.R. (1978) Changes in water potential during pressure bomb measurement. Agronomy Journal, 70, 353-355. 
This document is a scanned copy of a printed document. No warranty is given about the accuracy of the copy. Users should refer to the original published version of the material. 